\title{
Causes of Infertility among Sudanese Women in Khartoum State Sudan 2013
}

\author{
Nagat Sidig Yasin ${ }^{1}$ : Prof Mustafa Khidir Elnimeiri ${ }^{2}$ \\ ${ }^{1}$. Al Neelain University, Department of Obstetrics and Gynecological Nursing, Faculty of Nursing Sciences/ Al \\ Neelain University. \\ 2. Professor of Preventive Medicine and Epidemiology -Department of community Medicine Al Neelain Faculty \\ of Medicine and Health Sciences-Khartoum-Sudan.
}

\begin{abstract}
Background: Infertility is one of the most prevalent health disorders in young adults. Diagnostic assessment of infertility is indicated when pregnancy has not occurred within one year of regular unprotected intercourse.

The aim of the study; Overall aim of the study was to identify the causes of infertility among Sudanese women.

Materials and methods: Multi center-based cross sectional descriptive study design carried out at Khartoum state .the total number of participants include in this study were 162 infertile women. Data were collected using standardized administered questionnaire to assess causes associated with infertility among Sudanese women SPSS version 16 was used to analyze the collected data.

Results: Distribution of participants by Hyperprolactinemia showed there is no significant association with type of infertility $p$ value (0.37), also found that significant relation between PCOS (polycystic ovary syndrome) and type of infertility $p$ value (0.05), regard distribution of participants by tubal dysfunction and type of infertility seen no association $p$ value (0.57). Distribution of participants by ovulation disorders and pelvic inflammatory disease and type of infertility revealed no significant relation $P$ value $(0.11,0.15)$ respectively. And distribution of participants by toxoplasmosis infections showed highly significant association with type of infertility $P$ value (0.000).

Conclusion: The present study revealed that most common causes of female infertility are Hyperprolactinemia, PCOS (polycystic ovary syndrome, tubal dysfunction and toxoplasmosis were highly association by types of infertility. Ovulation disorders, pelvic inflammatory disease were not associated by types of infertility among Sudanese women.
\end{abstract}

Keywords: Infertility, Causes, Women Sudan.

\section{Introduction}

Infertility is one of the most prevalent health disorders in young adults. Diagnostic assessment of infertility is indicated when pregnancy has not occurred within one year of regular unprotected intercourse.[1] Infertility is a global health issue affecting approximately $8-10 \%$ of couples. It is a multidimensional problem with social, economic and cultural implications, which can take threatening proportions in countries with strong demographic problems[2]

According to the modern medicine, infertility has a wide range of causes Shabir et al., World J Pharm Sci 2015; 3(2): 361-367 362 stemming from three general sources: physiological dysfunctions, preventable causes, and unexplained issues. Anatomical, genetic, endocrinological and immunological problems can all cause or contribute to infertility. Female infertility can be due to Anovulation, Endocrine- amenorrhea, hypothyroidism, hyper prolactinaemia, hyper androgenism, premature menopause , Pathological defects tight/tender hymen, cervical stenosis, intracervical fibrous obstruction cervical polyp, hypoplasia of the uterus, anomaly of the uterus sub mucous fibroid/polyp or endometrial polyp. Endometritis, inflammatory tubal block, endometriosis, chocolate cyst, turner syndrome, Systematic, age, obesity, tobacco, psychological and Immunological - presence of anti-sperm antibodies in the cervical mucus[3].

\section{Materials and methods}

Multi center-based cross sectional descriptive design was conducted. This study was carried out in Nile Fertility Center (NFC), Khartoum Reproductive Health care Centre (KRHC), Sudan Assisted Reproductive Clinic (SARC) and Dr. Elsir Abuelhassan Center which are the largest centers provided assisted conception and modern antenatal care in Sudan. The study targeted all infertile women in reproductive age 15-49 years, from all Sudanese tribes and ethnic groups, all socioeconomic groups and religions. Four health centers from (9) centers were randomly selected, and then Proportional sample size was drawn from each selected center. The number participants of attending infertile women in each center were used to estimate the respective proportions total of 
162 infertile women were enrolled in the study.Was selected from each center by systematic random sampling technique. Data was collected by four trained research team using standardized administered questionnaire to assess the risk factors of infertility among Sudanese women. The data were analyzed using statistical package of social science (SPSS) version 0.16 and significance test was checked by chi-square $\mathrm{X}^{2}$ and the results was accepted when the P.value is $0.05 \%$ or less.

III. Results

Table (1): Ovulation disorders among participants versus type of infertility $(n=162)$.

\begin{tabular}{cccc}
\hline Ovulation disorders & Type of infertility & \multicolumn{2}{c}{ Total } \\
\cline { 2 - 3 } Yes & Primary infertility & Secondary infertility & \\
& 28 & 9 & 37 \\
No & $17.3 \%$ & $5.6 \%$ & $22.8 \%$ \\
& 79 & 46 & 125 \\
Total & $48.8 \%$ & $28.4 \%$ & $77.2 \%$ \\
& 107 & 55 & 162 \\
& $66.0 \%$ & $34.0 \%$ & $100.0 \%$ \\
\hline
\end{tabular}

$37 \%$ of participants had ovulation disorders

Table (2): Tubal dysfunction among participants versus type of infertility $(n=162)$.

\begin{tabular}{|c|c|c|c|}
\hline \multirow[t]{2}{*}{ Tubal dysfunction } & & Type of infertility & \multirow[t]{2}{*}{ Total } \\
\hline & Primary infertility & Secondary infertility & \\
\hline \multirow[t]{2}{*}{ Yes } & 16 & 8 & 24 \\
\hline & $9.9 \%$ & $4.9 \%$ & $14.8 \%$ \\
\hline \multirow[t]{2}{*}{ No } & 91 & 47 & 138 \\
\hline & $56.2 \%$ & $29.0 \%$ & $85.2 \%$ \\
\hline \multirow[t]{2}{*}{ Total } & 107 & 55 & 162 \\
\hline & $66.0 \%$ & $34.0 \%$ & $100.0 \%$ \\
\hline
\end{tabular}

P-value $=0.57$

$14.8 \%$ of participants had tubal dysfunction.

Table (3): Polycystic ovary syndrome (PCOS) among participants versus type of infertility ( $\mathrm{n}=162)$

\begin{tabular}{|c|c|c|c|}
\hline \multirow[t]{2}{*}{ (polycystic ovary syndrome) } & \multicolumn{2}{|r|}{ Type of infertility } & \multirow[t]{2}{*}{ Total } \\
\hline & Primary infertility & Secondary infertility & \\
\hline \multirow[t]{2}{*}{ Yes } & 36 & 11 & 47 \\
\hline & $22.2 \%$ & $6.8 \%$ & $29.0 \%$ \\
\hline \multirow[t]{2}{*}{ No } & 71 & 44 & 115 \\
\hline & $43.8 \%$ & $27.2 \%$ & $71.0 \%$ \\
\hline \multirow{2}{*}{ Total } & 107 & 55 & 162 \\
\hline & $66.0 \%$ & $34.0 \%$ & $100.0 \%$ \\
\hline
\end{tabular}

$29.0 \%$ of participants had PCOS (polycystic ovary syndrome)

Table (4): Hyperprolactinemia among participants versus type of infertility $(n=162)$

\begin{tabular}{cccc}
\hline Hyperprolactinemia & \multicolumn{2}{c}{ Type of infertility } & \multirow{2}{*}{ Total } \\
\cline { 2 - 3 } Yes & Primary infertility & Secondary infertility & \\
& 16 & 10 & 26 \\
No & $9.9 \%$ & $6.2 \%$ & $16.0 \%$ \\
& 91 & 45 & 136 \\
Total & $56.2 \%$ & $27.8 \%$ & $84.0 \%$ \\
& 107 & 55 & 162 \\
& $66.0 \%$ & $34.0 \%$ & $100.0 \%$ \\
\hline
\end{tabular}

P-value $=0.37$

$26.0 \%$ of participants had Hyperprolactinemia

Table (5): Pelvic inflammatory disease among participants versus type of infertility $(n=162)$

\begin{tabular}{cccc}
\hline Pelvic inflammatory disease & \multicolumn{2}{c}{ Type of infertility } & Total \\
\cline { 2 - 3 } Yes & Primary infertility & Secondary infertility & \\
& 31 & 21 & 52 \\
No & $19.1 \%$ & $13.0 \%$ & $32.1 \%$ \\
& 76 & 34 & 110 \\
Total & $46.9 \%$ & $21.0 \%$ & $67.9 \%$ \\
& 107 & 55 & 162 \\
& $66.0 \%$ & $34.0 \%$ & $100.0 \%$ \\
\hline
\end{tabular}

P-value $=0.15$

$32.1 \%$ of participants have pelvic inflammatory disease. 
Table (6): Toxoplasmosis infection among participants versus type of infertility $(n=162)$

\begin{tabular}{cccc}
\hline toxoplasmosis infection & Type of infertility & \multicolumn{2}{c}{ Total } \\
\cline { 2 - 3 } Yes & Primary infertility & Secondary infertility & \\
& 0 & 8 & 8 \\
No & $.0 \%$ & $4.9 \%$ & $4.9 \%$ \\
& 107 & 47 & 154 \\
Total & $66.0 \%$ & $29.0 \%$ & $95.1 \%$ \\
& 107 & 55 & 162 \\
& $66.0 \%$ & $34.0 \%$ & $100.0 \%$ \\
\hline
\end{tabular}

$4.9 \%$ of participants have toxoplasmosis infection.

\section{Discussion}

Twenty-two point eight percent of participants had ovulation disorders, while seventeen point three percent were primary infertility and only five point six percent were secondary infertility, there is no statistically significant association between types of infertility and ovulation disorders P-value $=0.11$ according to table (1). Previous epidemiological study have showed that 10-27\% have ovulatory dysfunction [4]. On the other hand ovulation disorders associated with infertility according to literature review $[4,5]$.

Fourteen point eight percent of participants had tubal dysfunction. Nine point nine percent of participants were primary infertility, while four point nine percent of participants were secondary infertility. There is no statistically significant association between types of infertility tubal dysfunction P-value $=0.57$ as in table (2). The present study disagree with results of Roupa $\mathrm{Z}$ et al (2009), twenty seven point four percent of the problems were due to fallopian tubes dysfunction[2]. and Sule J.O et al (2008), their findings are thirty nine point five percent [6] All tubal factors can lead to infertility according to literature review [5].

In the present study polycystic ovarian syndrome about one third of participants, twenty two point two percent were primary infertility and only six point eight percent were secondary infertility. There is statistically significant association between PCOS (polycystic ovary syndrome) and types of infertility P-value $=0.05$ according to table (3). This current results dissimilar with the findings of 1Sule J. O et al. where ovarian factor $13.0 \%$ [6]. Also differ from Roupa $\mathrm{Z}$ et al, where ovarian deficiency were $3.6 \%{ }^{(7)}$ and Nousheen Aziz (2010) findings were $15.6 \%$ in case of primary infertility and not found in cases of secondary infertility [6] Polycystic ovaries syndrome (PCOS) is usually a hereditary problem and accounts for up to $90.0 \%$ of cases of unovulation. In PCOS the ovaries produce high amounts of androgens, particularly testosterone and thus amenorrhea or oligomenorrhea is quite common, according literature review [5].

In current study Hyperprolactinemia, nine point nine percent of participants were primary infertility while six point two percent were secondary infertility. There is no statistically significant association between Hyperprolactinemia and types of infertility P-value $=0.37$ as in table (4). The current study dissimilar with previous study conducted in Gezira State by Salah Eldin A. AbdElghani and et al ( $\mathrm{P}=0.000$ [8]. According to literature review Hyperprolactinemia causes infertility by increasing the release of dopamine from the hypothalamus which inhibit Gonadotrophin- releasing hormone $(\mathrm{GnRH})$ and thus gonadal steroid genesis and eventual infertility[5,9].

About one third $32.1 \%$ of participants had pelvic inflammatory disease, thirty one (19.1\%) of participants were primary infertility and twenty one (13.0\%) were secondary infertility, there is no statistically significant association between types of infertility P-value $=0.15$ as in table (5). But actually infection of the pelvic organs can cause severe illness and may lead to tubal blockage and pelvic adhesions leading to infertility according to literature review [5,10,11]. The present study disagree with A.J. Pavletic et al ,their findings were, Nineteen $(40 \%)$ of the 48 women not using contraception were involuntarily infertile after the index episode of pelvic inflammatory disease (P 0.02)[12].In present study the frequency of pelvic Inflammatory disease (PID) was $(32.1 \%)$ this dissimilar to results found by Nousheen Aziz et al. (2007).Pelvic inflammatory disease (PID) was found in $(8.0 \%)[2]$.

Four point nine percent of participants developed only secondary infertility regarding toxoplasmosis infection this considered (100\% of infertility in this present study), there is a highly statistically significant association between toxoplasmosis infection and secondary infertility P-value $=0.00$ as in table (6), the findings of present study are similar to other studies done in Egypt, their findings recorded a statistically significant higher $(p<0.01)[13]$. This infection can affect female fertility by causing repeated abortion if not treated totally.

\section{Conclusion}

Infertility is multifactorial in nature and several causes are associated with its occurrence. The present study revealed that most common causes of female infertility among Sundance women are Hyperprolactinemia, PCOS (polycystic ovary syndrome, tubal dysfunction and toxoplasmosis were highly association by types of 
infertility. Infertility should be taken into consideration in terms of reproductive health needs, early detection and treatment of any gynecological diseases especially toxoplasmosis infection and PCOS by regular checkup and provide sensitive counseling for high risk individual to avoid inappropriate treatment and discourage for seeking from different clinic.

\section{References}

[1] Farhi J. Haroush BA. Distribution of causes of infertility in patients attending primary fertility clinics in Israel IMAJ • VOL $13 \cdot$ JANUARY 2011;13 (1):51-4 .Available at https://www.ncbi.nlm.nih.gov/pubmed/21446238. Accessed on 1/6/2017.

[2] Roupa Z, Polikandrioti M, Sotiropoulou P, Faros E, Koulouri A, \& Wozniak G. Causes of Infertility in Women at Reproductive Age, Health Science Journal (HSJ) 2009 VOLUME 3, ISSUE 2 .P .80-8 ISSN:1108-7366,,E-ISSN:1791-809X available At: http://www.hsj.gr/medicine/causes-of-infertility-in-women-at-reproductive-age.pdf Accessed on 24 /5/2017.

[3] Bhat, A S. Raza A , Wani P, Shahabuddin M.. Women's infertility-A Unani Prospective World Journal of Pharmaceutical Sciences ISSN (Print): 2321-3310; ISSN (Online): 2321-3086 Published by Atom and Cell Publishers @ All Rights Reserved. Received: 1801-2015 / Revised: 27-01-2015 / Accepted: 01-02-2015 Available online at: http://www.wjpsonline.org/ file:///C:/Users/MY\%20HP/Downloads/jL1q3X.pdf Accessed on 1/6/2017.

[4] yakass M B. possible causes of infertility in patients visiting an IVF clinic and the use of basal Gonadotrophin as predictive markers of ovarian response in IVF clients, September, 2013. Available at: http://dspace.knust.edu.gh/bitstream/123456789/5365/1/MICHAEL\%20BRIGHT\%20YAKASS.pdf.Accessed on 18/12/13

[5] Eniola O W, Adetola A A, Abayomi BT. A review of Female Infertility; important etiological factors and management. Journal of. Microbiol. Biotech. Research. 2012, 2 (3):379-385.Available online at: www.scholarsresearchlibrary. Comk. http://www.scirp.org/(S(vtj3fa45qm1ean45vvffcz55))/reference/ReferencesPapers.aspx?ReferenceID=1706846.Accessed on 21/1/2017.

[6] Sule JO, Erigbali P . Eruom L. Prevalence of Infertility in Women in a Southwestern Nigerian Community. African Journal of Biomedical Research, May 2008 . Vol. 11 (2008) ; 225 - 227ISSN 1119 - 5096 (C) Ibadan Biomedical Communications Group. Received: September 2006 .Accepted (Revised):August 2007Published May 2008 .Available at : http://www.ajbrui.com Accessed on $10 / 3 / 2014$.

[7] International Ashermans Association. What is Asherman's Syndrome? Available at:https://www.fertilityshow.co.uk/why-thefertility-show/our-exhibitors/detail/international-ashermans-association .Accessed on 10/3/2014.

[8] Ahmed SE, Abdelgadir AA, Elmugadam, Mohammed M E ,Hyperprolactinemia as a cause of female primary infertility and its prevalence in Gezira State, Central Sudan, Physiology \& Molecular Biology. Egypt. Acad. J. Biolog. Sci., 5(1): 31 -36 (2013) Biology ISSN: 2090-0767 Received: 15 / 5 / 2013. Received: 15 / 5 / 2013. Available at www.eajbs.eg.net. Accessed on 9/3/2014.

[9] Kaiser B, Massachusetts. Boston. Hyperprolactinemia and infertility. Brigham and Women's Hospital USA. January 14/2017.The Journal of Clinical Investigation http://www.jci.org Volume 122 Number 10 October 2012 DOI.org/10.1172/JCI64455.Available at: https://www.jci.org/articles/view/64455/version/2/pdf/render. Accessed on 24/1/2017.

[10] World Health Organization. Sexual and reproductive health .Available at: http://www.who.int/reproductivehealth/en/.Accessed on $23 / 5 / 2017$.

[11] Illinois Department of Public Health. Pelvic inflammatory disease (PID). HIV/STD Hotline 800-243-2437 (TTY 800-782-0423). Available At http://www.dph.illinois.gov/topics-services/diseases-and-conditions/diseases-a-z-list/pelvic-inflammatory-disease. accessed on $3 / 4 / 2016$.

[12] Pavletic A J, HanssenP,W61ner,PaavonenJ, HawesSE and Eschenbach DA. Infertility Following Pelvic Inflammatory Disease.Infectious Diseases in Obstetrics and Gynecology 7:145-152 (1999) (C) 1999 Wiley-Liss, Inc. Received 31 August 1998 Clinical Study Accepted 5 January1999 Available at https://www.ncbi.nlm.nih.gov/pubmed/10371473.Accessed on3/2/2015.

[13] El-Tantawy N, Taman A and Shalaby H. Toxoplasmosis and Female Infertility: Is there a Co-Relation?. American Journal of Epidemiology and Infectious Disease, vol. 2, no. 1 (2014): 29-32. doi: 10.12691/ajeid-2-1-6.) Available online at http://pubs.sciepub.com/ajeid/2/1/6 Accessed on 22/1/2615. 